WellBeing International

WBI Studies Repository

$12-2003$

\title{
Ethical Issues in the Use of Animals in Biomedical and Psychopharmocological Research
}

\author{
John P. Gluck \\ University of New Mexico \\ Jordan Bell \\ University of New Mexico
}

Follow this and additional works at: https://www.wellbeingintlstudiesrepository.org/acwp_arte

Part of the Animal Experimentation and Research Commons, Animal Studies Commons, and the Other Pharmacy and Pharmaceutical Sciences Commons

\section{Recommended Citation}

Gluck, J. P., \& Bell, J. (2003). Ethical issues in the use of animals in biomedical and psychopharmocological research. Psychopharmacology, 171(1), 6-12.

This material is brought to you for free and open access by WellBeing International. It has been accepted for inclusion by an authorized administrator of the WBI Studies Repository. For more information, please contact wbisr-info@wellbeingintl.org.

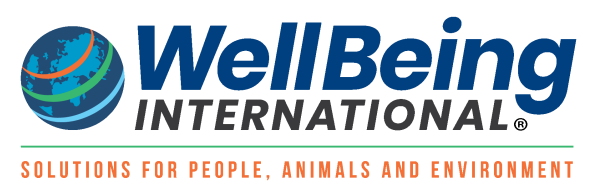




\title{
Ethical Issues in the Use of Animals in Biomedical and Psychopharmocological Research
}

\author{
John P. Gluck ${ }^{1,2}$ and Jordan Bell ${ }^{1}$ \\ ${ }^{1}$ University of New Mexico \\ ${ }^{2}$ Georgetown University
}

\section{KEYWORDS}

ethics, psychopharmacology, animal research, animal models, validity, moral standing

\begin{abstract}
$\underline{\text { ABSTRACT }}$
Rationale: The ethical debate concerning the use of animals in biomedical and pharmacological research continues to be replete with misunderstandings about whether animals have moral standing. Objectives: This article briefly reviews the central ethical positions and their relationship to the basic parameters of research regulation from an international perspective. The issues associated with the validation of animal models will then be discussed. Finally, suggestions for empirical ethics research will be presented. Methods: Recent literature reviews were accessed and analyzed. Results: This review summarizes the pertinent ethical and research literature. Conclusions: In summary, regardless of the ethical perspective one favors, there is strong agreement that animals matter morally and that at a minimum their welfare must be considered. This position is reflected in the structure of national regulatory schemes that emphasize the three Rs (replacement, reduction, refinement). Researchers should more actively participate in the discussion by becoming more knowledgeable about the details of the ethical issues. Research with animal models has been problematic in that it has often focused on attempting to produce global models of psychiatric disorders, which suffer from inherent validity problems. Researchers must also become more sophisticated about issues of model validation and the nature of the animals they use.
\end{abstract}

\section{Introduction}

While there is certainly a long and productive history of using animals in biomedical and psychopharmacological research, the debate concerning its ethical justification continues to lack clarity (see Rollin 1989; De Grazia 1991; Beauchamp 1997; Gluck and DiPasquale 2002). Given the continued 
degree of contention inherent in the debate, it has been increasingly recognized that as researchers, we need to improve our sophistication about the ethical issues in question and scientifically and ethically evaluate our use of animals (Gluck and Kubacki 1991; Goodman and Check 2002). In this paper we will address this situation by reviewing three areas. We will first review the essential philosophical elements of the ethical controversy. Next we will briefly consider the impact of the ethical discussion on the governmental regulation that we are beginning to see internationally. Finally we review the issues that evolved concerning the usefulness of animal models in the major neuropsychiatric dysfunctions. We will describe the success of older modeling approaches and the more recent methodological trends. Finally, we will discuss some of the ways the ethical discussion needs to be incorporated into the practice of psychopharmacological research.

\section{Do animals have moral standing?}

To begin with, the notion of "standing" comes to us from law, where the issue is related to whether an individual has the status to bring forth some form of legal action. If Smith's neighbor Jones fails to properly trim her tree and it falls and crushes Smith's car and then Jones refuses to repair it, the question becomes whether Smith has standing to bring a legal action against Jones. In this case, Smith gets access to the legal system by virtue of the fact that she has the status of taxpayer, car owner, citizen, and has apparently suffered a direct loss because of her neighbor's negligence. In other words, standing in the legal sense permits access to the law and its mechanisms to evaluate and redress a claim. Extending from this example to the question about whether animals have moral standing requires us to determine what characteristics an entity must possess in order to achieve the status necessary to access the protections provided by the moral and ethical standards of a society. What are those characteristics that provide this access? It is here where ethical theorists have a variety of perspectives.

\section{Utilitarian ethical theories}

These theories turn on the notion that if an action is to be considered right it must be one that is drawn from the population of possible responses that produces the greatest amount of good for the collection of individuals affected by the act. The onus on the ethical decision maker is to strive to maximize the amount of aggregate good (the principle of utility). To do this, the decision maker is required to calculate impartially the consequences of a given choice on all those affected. Therefore, in order to be counted as an entity that has moral standing a being must possess at least some rudimentary ability to experience a consequence. That is, it must have the ability to experience pain and pleasure, have preferences, or have a welfare that matters to it. As Jeremy Bentham (1748-1832) put it, an entity is not required to possess some high level of cognitive ability like thinking, intention or rationality but only the ability to suffer. That characteristic alone is sufficient to be considered relevant for ethical consideration. The possession of higher or more complex cognitive abilities do come into play as these abilities potentially increase the variety of ways that an individual may be pleased or harmed. Therefore, all sentient lives count, but not all lives necessarily have the same value because the overall value of a life increases as the richness (the ways that the entity can pleasured or harmed) of that life increases. The converse is also true. "If a being is not capable of suffering, or of enjoyment, there is nothing to take into account" morally (Singer 1990, $p$. 171). In a related approach, Raymond Frey (2002), a strong advocate for the use of animals in research, agrees that if the value of a life parallels the emergence of capabilities such as intelligence, sentience, and self-direction, the value of that life also increases and deserves increasing levels of ethical consideration. Frey, however, wants us to recognize that there are some humans whose quality of life is below that of some animals [e.g. say between a human in a persistent vegetative state (PVS) with no living relatives or friends and a healthy chimpanzee living in a social group in west Africa]. Assume for a moment that from a physiological perspective both are appropriate subjects for a particular research project. In this unique case, according to Frey, the greater level of protection should go to the chimpanzee 
because its life is of a higher quality. In other words, Frey insists that the implications of the utilitarian perspective be carried out consistently regardless of species membership because he cannot see how species membership divorced from these capabilities can matter morally. To make species membership matter one must leave the domain of secular ethics and enter the realm of specific religious doctrine.

To summarize, this perspective does not disallow the use of animals in biomedical research in general, and psychopharmacological research in particular. Nor does it prevent the use of humans. What is required, however, is a high level of justification based upon a realistic and good faith assessment of the benefits of the research and the harmful impact on research subjects. In a recent opinion piece in the June 13, 2002 issue of Nature, entitled "Distasteful But Necessary," this point is emphasized in a discussion about the use of primates in biomedical research. The piece explicitly calls for an evaluation of whether the benefits of drug toxicity tests that are currently carried out on nonhuman primates are ethically justified "bearing in mind that primates may have a greater capacity for suffering than other animals."

\section{Kantian or deontological theories}

Theories of this sort reject the consequentialist calculation method of evaluating the ethical acceptability of actions. What matters here instead is the evaluation of the acceptability of the moral rule on which an action is based, regardless of the consequences. Immanuel Kant's (1724-1804) notion of the "categorical imperative" requires that we act only in such a way that the maxim which grounds a particular action could be taken as a universal law, to be followed under all similar circumstances and times. So assume that I run out to pick up my newspaper early in the morning because I have an important need to know if the city council made a particular vote the previous evening. However, I discover that my paper is not there. Am I permitted to take my neighbors instead? Assume that I judge that the benefits to me, my business, and the financial welfare of my family far outstrip the costs to my neighbor, since I know that he rarely reads the paper in the first place. From a utilitarian perspective, I am in fact obligated to steal my neighbor's newspaper in this situation. For Kant, in order for me to justify taking the paper I must be willing to say that I would sanction the act of stealing whenever a person honestly believes that someone else's property would do them more good than the owner. In other formulations of the categorical imperative, more relevant to our current discussion about research participation, Kant states that morality requires that we treat human persons as "ends in themselves" and never merely as means to our ends. Kant based this position on the belief that only humans were persons capable of moral and ethical deliberation of the kind that could result in the discovery of moral law. Only humans could become part of moral communities where our treatment of one another could be argued, debated and resolved. Only humans were autonomous "to give oneself the law" and therefore only humans rightfully have access to the protections afforded by ethical norms.

While Kant was quite clear in his writing that he believed that humans had no primary ethical responsibilities to animals, he did believe that we had secondary ethical responsibilities to them. In other words, Kant believed that the way we treat animals could become relevant to the way we treat humans and therefore morally important. If we treated "dumb" animals with cruelty, he felt that there was an increased probability that we would do the same to humans. In that way, and that way only, our treatment of animals was morally relevant.

In general, while pure Kantian perspectives about animals (i.e. no direct obligations) are quite rare, many other ethical perspectives have been influenced by Kant at least in that they require that an entity have demonstrated higher levels of cognitive ability to be considered to have moral standing. The list of characteristics stemming from these considerations includes consciousness, self-awareness, rationality, autonomy, and the ability to have second-order intentions (i.e. the ability to have intentions about one's 
intentions). The argument goes that characteristics such as these are required to make morality a possibility in the first place. Where we draw the line on the list of characteristics has significant implications. If we draw the line at the low end of complexity-say, basic consciousness-it would have the effect of ensuring that all intact humans have moral standing. It would also have the effect of covering many animals as well. On the other hand, if we draw the line higher, say at the level of having an awareness of self through time or second-order intentions, that would leave all or most animals out, except for perhaps the great apes, but would also leave some humans out as well (e.g. PVS patients, anencephalic infants). When Goodman and Check (2002), in their review of the debate about the use of the so-called higher primates in research, point out that the very characteristics that make primates desirable research subjects also triggers questions about the ethical justification of the practice, they are emphasizing the influence of these types of considerations.

\section{Arguments from inherent value and rights}

Perhaps the best exemplar of this thinking can be found in the work of Tom Regan. In his influential work "The case for animal rights" (1983), Regan proposes that as long as there is something it is like to be a particular organism, the ability to experience that "something" bestows inherent value to that being. This is what Regan refers to as being a "subject of a life," which bestows rights. The existence of those rights protects against intrusions by humans seeking to take hold of and use that life for their own purposes, no matter how well intentioned the planned use may be. The implication here is that unless a being specifically consents to participation in research, science and society are required to find alternatives ways of discovery. While these perspectives reflect important considerations, they offer no middle ground and are therefore not likely to move the discussion along to resolution.

\section{Speciesism}

Up to this point we have seen that being a member of a particular species has not yet been emphasized as relevant to the protection afforded by ethical norms. To base access on species membership alone has been referred to as speciesism by Peter Singer (1975) and is meant by him to be a derogatory characterization similar to sexism or racism. This is a difficult issue. Certainly, some important philosophers (e.g. Mary Midgely 1984; Carl Cohen 1986) have argued that having a preference for one's own kind is understandable and is, to at least some extent, ethically acceptable. However, this move toward ethically favoring "our own" has serious downside potential. For example, if we let that argument stand without qualification, what is to prevent others from using this standard to make acceptable special treatment of their "own kind" over non-group members this time based not on characteristics like species membership but on color, gender, race, or ethnicity? Clearly some uses of the "our own" argument are extremely problematic. In addition, Sapontzis (1987) points out that the history of ethics and moral philosophy has been one characterized not by a hardening of boundaries between protected groups, but by an ever widening of the circle of inclusion. As we have seen in our discussion of utilitarian and Kantian theories, each incorporates different decisional strategies that help to support an emphasis on the characteristic of impartiality. The problem ethically then is find the balance between acceptable partiality and impartiality.

As the discussion shows clearly, the tendency of ethicists has been to put a heavier emphasis on the relationship between cognitive and sentient characteristics and the level of deserved moral protection. This fact is of particular importance to pharmacological research as many of the traditional uses of animals are based upon the assumption that animals are capable of experiencing complex emotional and cognitive states such as helplessness, depression, anxiety, and perhaps even psychotic symptoms. 


\section{Clearly pro-use perspectives}

Adrian Morrison, a prominent neuroscientist and veterinarian, while admittedly not formally trained in moral philosophy, has become established as a respected authority for the ethical justification of pro-use positions. It is important to consider his influential perspectives. While acknowledging that researchers have strong obligations to care for animal welfare when we restrict their lives for our purposes, he is unambiguous about his support for the extensive use of animals in biomedical research. The ethical base of his arguments (Morrison 2001, 2002) focus on the following four points:

1. Animal research has produced enormous benefit for the physically and mentally ill and is necessary for continued biomedical advance.

2. Our primary obligations are to our fellow humans.

3. All human beings are persons but animals are not persons.

4. Humans get to decide what animals are to be in relationship to us.

There are many strengths in Morrison's general arguments. For example, he effectively maintains the specter of disease and human suffering clearly before us. He highlights the many successes that have emerged from animal research, like the development of psychotropic medications. He reminds researchers of their obligations to laboratory animals and the relationship between good animal welfare and good science. He is also a poignant critic of Peter Singer's brand of utilitarianism and his low evaluation of the value of the lives of some severely disabled humans. The weaknesses of Morrison's ideological problem, as exemplified by analysis of the four points above, are that he tends to include the elements of various ethical theories that support his beliefs while excluding other aspects that would make his conclusions more debatable. For example, on one hand he criticizes the impartiality of utilitarian thinking (e.g. Singer), but then grounds the justification of animal research firmly within the principle of utility (no. 1). He adopts the concept of personhood as the criterion for moral standing (no. 2), but does not deal with the ethical implications of the scientific data coming to us about the nature of animal cognitive ability provided by ethologists and comparative cognitive psychologists. These data provide evidence of the existence in animals of many of the very cognitive characteristics that have traditionally served as the definition of human persons (see Griffin 1981, 1984, 1992; Hauser 2000). Instead, he simply declares that evolutionary considerations do not apply to the domain of the mental (no. 4). The danger of Morrison's certainty is that it could result in some researchers being lulled into a sense of security about the clarity of the ethical debate. This contradicts a recent editorial in the July issue of the journal Nature Neuroscience (2002), which calls upon us as scientists to become increasingly sophisticated about the ethical issues involved with our work.

Except for the limited version of the Kantian position, there is wide agreement that animals matter morally. Utilitarians demand that we include the consequences of our interactions with them into the justificatory process. Kantian-influenced arguments require that we access the implications of the cognitive abilities that we find in animals and determine whether they reach the level that requires that we modify or forebear from the invasive interactions that may follow from our work. Even those writers that exclude animals from membership in the moral community agree that our treatment of them for good purpose be marked by sensitivity and respect. There is also widespread agreement that research on animals should involve the fewest number, at the level of the least pain possible, and then only when there is no valid alternative. These agreements follow closely on the proposals of Russell and Burch (1959) which are referred to as the "three Rs" (reduction, refinement, replacement).

Others (e.g. Epling 1989) have pointed out that some of the very animals whose welfare researchers are required to protect, receive very different treatment if encountered outside the laboratory. Thus "pest" mice are exterminated brutally while the use of laboratory mice for research must be carefully justified 
with concern for minimizing their pain and distress clearly demonstrated. It is then argued that this paradox is clear evidence that the need for ethical justification of animal research is patently absurd. This criticism fails to recognize that in general, the application of broad ethical principles (e.g. "do no harm") must be made relevant to the details of a particular real life situation under consideration. Conduct appropriate to this principle in some contexts may require modification in other circumstances. Clearly our ethical obligations to animals (and humans for that matter) who pose a real danger to our well-being are justifiably different than when those same animals pose no such risk. Let us suppose that we were to discover that an official responsible for the extermination of mice for public health purposes was found to be slowly frying the animals alive in large skillets in order to prolong their suffering. Would we not find that to be objectionable? While the risk to the public health may justify extermination it certainly does not remove the animals from some basic forms of ethical consideration (Gluck and Kubacki 1991).

\section{Regulatory perspectives}

There is no question that ethical theory has influenced the development of national regulatory approaches in that all such approaches provide certain limitations and protections for animals used in biomedical research. In so doing, they acknowledge that animals deserve ethical consideration. However, the extent of the consideration varies considerably. Looking broadly, 23 countries currently have some form of animal research legislation. The countries included in this group are Australia (some states), Austria, Belgium, Denmark, Finland, France, Germany, Greece, Iceland, Ireland, Italy, Luxembourg, the Netherlands, New Zealand, Norway, Poland, Portugal, Spain, Sweden, Switzerland, Taiwan, the United Kingdom, and the United States (Orlans 2002). Orlans (2002) has developed a list of eight characteristics on which the various legislative attempts can be graded. She argues that a country with all eight characteristics represents the highest form of protection while not at the same time excluding the practice (the principality of Liechtenstein is the only country that currently outlaws all forms of animal research or testing). The characteristics are:

1. The provision of basic husbandry requirements and the regular inspection of facilities by an independent review group.

2. Requirements that mandate the control of pain and suffering.

3. Critical pre-review of research proposals.

4. Requirements for investigator competence.

5. Bans on certain procedures, levels of pain and distress, sources of animals, and use of some species.

6. Application of the three Rs.

7. The use of ethical criteria in the justification and decisional process.

8. Requirements that require investigators to rate the level of expected harm to the animals.

Orlans points out that as time passes, the tendency of national regulations is to incorporate more and more of this list and not less. When the United States Animal Welfare Act (AWA) is compared with European standards, the central difference is related to the question of whether there are any limits to what can be done to an experimental animal in the name of science (item no. 5). In the United States, other than for performing surgery with non-anesthetic paralytic agents, any investigative procedure producing any level of pain can conceivably be approved if the argument for benefits is sufficiently credible. In other words, there is no point where animal interests rise to the level of trumping the search for human benefit. On the other hand, in the United Kingdom the ethic has moved to the position that experimental procedures that produce extreme levels of pain and distress are not permitted regardless of the predicted benefits. In general, the standards of the overall European Community do not rise to that level of protection but do require that research where harms are not balanced by benefits must not proceed (see Brody 1998). 


\section{The use of animals in psychopharmacological research}

Researchers involved in the process of developing pharmacological treatments for neuropsychiatric disorders by studying animal models face a daunting task from both the scientific and ethical realm. The scientific challenges involve the unraveling of the cognitive, behavioral and affective manifestations of complex disorders that often substantially exist in the realm of the subjective and are mediated by the most complex of all physiological systems. From an ethical perspective, as we have seen, it is becoming widely accepted that the existence of a sentient "mental" life leads to moral standing and, as the complexity increases, so does the level of deserved protection. This reflects directly on the use of animals as global models of these disorders, as the very characteristics that make them potentially useful brings them increasingly under the protection of ethical norms. What adds to the ethical difficulty is that the use of animals in the study of psychiatric disorders has a long history where the ethical issues that we now are beginning to appreciate were not significant factors in research planning.

Early in the twentieth century, the Nobel Laureate Ivan Pavlov proposed that the production of abnormal behavior in animals would be a useful direction to take in attempting to improve the scientific validity of the methods of treatment available to human psychiatric patients. For example, the experiments from his laboratory by Shenger-Kerstovnikova (1921) demonstrated that dogs required to solve a series of increasingly more difficult circle-ellipse discriminations eventually developed an "experimental neurosis." It was later found (Babkin 1938) that the neurotic symptoms were alleviated by the administration of bromides and that the treatment was also effective in human children.

The animal model research that followed on the heels of these discoveries built on the idea that abnormal behaviors could be readily produced and studied in animals by using a two-stage procedure. During stage 1 , an animal was trained to learn a specific adaptive response to a particular environmental situation. In stage 2, the environment to which the animal had become adapted was changed in such a way that the previously adaptive response was placed in conflict. For example, Masserman (1946) conditioned cats to express a simple response to get food from a covered dish. After the animal was thoroughly trained, it was then punished by with a painful stimulus when it emitted this previously adaptive response. The animals appeared to develop a phobia so strong that they would have starved to death rather than approach the feeding device again.

What we see developing here is the idea of the importance of animal models whose validity was based upon the presumed etiology of human abnormal behavior (i.e. Freudian intrapsychic conflict) along with those symptoms that had a structural or functional similarity to the human expression. These were attempts to recreate the model of a disease state in its entirety. The model was then used as a testing ground for experimental interventions. This approach to animal models was dominant for many years. Ethical issues generally were not confronted at this time. Contemporary consideration of such issues now require a stringent assessment of the validity of the model, not just for its usefulness to the disorder of interest, but also so model validity can be measured against the harms produced in the experimental animal.

\section{Issues of validity and ethical justification}

In the most fundamental sense, the ethical justification for the use of animals requires that their use result in benefits for humans and perhaps animals as well. Therefore, the assessment of the validity of animal models is crucial. Geyer and Markou (1995) have forcefully emphasized that justification must in the end focus on reliability and predictive validity. In other words, if the model does not lead to useful predictions about the human clinical condition, it ought to be abandoned no matter how conceptually appealing the model may be. When a researcher attempts to create a model that resembles a psychiatric syndrome in 
its entirety, it requires establishing the existence of a homology between the relevant animal behavior and the syndrome being modeled. As we have seen, these types of approaches were characteristic of the early years and continue to some extent today. The approach is scientifically problematic and therefore ethically problematic for a number of reasons. One difficulty stems from the reliance on arguments of validity based upon apparent similarities (i.e. face validity). Such arguments are deficient because the central symptoms of a given disorder are frequently defined in subjective terms and hard to translate to the purely observable behavior of animals. Second, as our understanding of a disorder advances, the defining criteria of that disorder also tend to change. In other words, what may have appeared to be an overall model at one point in time may turn out to be grossly inadequate as our understanding of the clinical phenotype evolves. In addition, the costs to animals involved in this research may also be extraordinarily high because the intervention tries to produce an entire complement of symptoms. For example, the social isolation model of depression in primates proposed by Harry Harlow (see Harlow et al. 1971) resulted in extreme social, cognitive, and personal behavior deficits in the experimental animals with little resulting benefit to the understanding of the clinical condition (Willner 1995). Similarly, Kilts (2001) states emphatically that despite decades of study of holistic animal models of schizophrenia, they have produced no new diagnostic or medication advances. These concerns suggest that the creation of global models, if they are ever appropriate, ought not to come too early in the investigational process, but only after human clinical understanding of the profile of the condition is more certain. In these situations the typical procedural norm that animal research should always precede human research may not be either scientifically or ethically justified.

Newer approaches to animal modeling rely on producing the specific signs, symptoms, or components of the psychiatric condition rather than the reproduction of a syndrome in its entirety (Geyer and Markou 1995). This approach allows for in-depth investigations of the underlying mechanisms of the specific syndromal signs and strengthens the capacity to evaluate validity issues. McClearn (1979) suggested that partial models that are focused on some portion of the overall clinical picture be referred to as "simulacra" to emphasize the limited focus of the model. He contended that when simulacra are derived from a careful consideration of an important human clinical phenomenon, the models can be justified as their contributions could be useful adjuncts to understanding.

These validity issues highlight the necessary mutual dependency of human and animal research in this area. Without extensive human clinical information, animal researchers cannot properly target their research models, and their scientific and ethical justification is thereby weakened. Therefore it is imperative that researchers and ethicists work through the ethical issues related to studying clinical populations where informed consent is problematic (Roberts et al. 2000).

\section{Choice of species}

While the choice of animals for use in model research has ethical implications, all too often the selection is based on factors such as ease of availability rather than the model-relevant characteristics (Gluck 1997). Overall and colleagues (1994) have shown that when investigators have broad expertise in animal behavior it can lead to the discovery of powerful naturally occurring models. These researchers capitalized on the clinical veterinary literature that strongly suggests that dogs suffer from a wide variety of anxiety disorders such as separation anxiety, obsessive-compulsive disorder, post-traumatic stress disorder, panic attacks, and thunderstorm or noise phobia. These models have begun to provide important information and insight into the complex neurobiological and genetic elements leading to anxiety behaviors. Importantly, the research has also benefited many companion animals that suffer from anxiety problems. 


\section{Topics for empirical ethics research}

Areas of empirically oriented research abound and include the following:

1. What are the educational needs of researchers that would improve their appreciation and understanding of the ethics issues?

2. What formats would be most effective in presenting and discussing the issues?

3. How well do animal researchers understand the human clinical literature that grounds their work? How is that knowledge best improved?

4. How well do researchers understand the formal process of model validation?

5. Do researchers believe that there are procedures that ought not to be conducted regardless of the potential benefits?

\section{Conclusions}

In summary, regardless of the ethical perspective one favors, there is strong agreement that animals matter morally and that at a minimum their welfare must be considered in the design of research, not just out of personal sense of caring, but from ethical obligation and duty. This position is supported by the ever-expanding proliferation of national regulatory schemes which are primarily based in the three Rs. Researchers must not leave the analysis of these issues solely to others whose positions seem to capture our preferences, for they turn out on close examination to be questionable prejudices. Research with animal models has been problematic in that it has often focused on attempting to produce global models of psychiatric disorders, which suffer from inherent validity problems. Researchers must become more sophisticated about issues of model validation and the nature of the animals they use.

\section{References}

Babkin BP (1938) Experimental neuroses in animals and their treatment with bromides. Edinb Med J 45:605-619

Beauchamp T (1997) Opposing views on animal experimentation: do animals have rights? Ethics Behav 7:113-21

Brody B (1998) The ethics of biomedical research: an international perspective. Oxford University Press, New York

Cohen C (1986) The case for the use of animals in biomedical research. N Engl J Med 315:865-70

De Grazia D (1991) The moral status of animals and their use in research: a philosophical review. Kennedy Inst Ethics J1:48-70

Epling W (1989) Rats. Behav Anal 12:251-253

Frey R (2002) Ethics, animals, and scientific inquiry. In: Gluck JP, DiPasquale T, Orlans FB (eds) Applied ethics in animal research: philosophy, regulation, and laboratory applications. Purdue, West Lafayette, pp 13-24

Geyer MA, Markou A (1995) Animal models of psychiatric disorders. In Bloom FE, Kupfer DJ (eds) Psychopharmacology: the fourth generation of progress. Raven, New York, pp 787-798

Gluck JP (1997) Learning to see the animals again. In: Lafollette H (ed) Ethics in practice. Blackwell, London, pp 160-167

Gluck JP, DiPasquale T (2002) Introduction and overview. In: Gluck JP DiPasquale T, Orlans FB (eds) Applied ethics in animal research: philosophy, regulation, and laboratory applications. Purdue, West Lafayette, pp 1-11

Gluck JP, Kubacki SR (1991) Animals in biomedical research: the undermining effect of the rhetoric of the besieged. Ethics Behav 1:157-173

Goodman S, Check E (2002) Animal experiments: the great primate debate. Nature 417:684-687 
Griffin D (1981) The question of animal awareness. Rockefeller University, New York

Griffin D (1984) Animal thinking. Harvard University, Cambridge

Griffin D (1992) Animal minds. University of Chicago, Chicago

Harlow HF, Harlow MK, Suomi SJ (1971) From thought to therapy: lessons from a primate laboratory. Am Sci 59:538-549

Hauser M (2000) Wild minds. Henry Holt, New York Kilts CD (2001) The changing roles and targets for animal models of schizophrenia. Biol Psychiatry 50:845-855

Masserman JH (1946) Principles of dynamic psychiatry. Saunders, Philadelphia

McClearn G (1979) Genetics and alcholism simulacra. Alcohol Clin Exp Res 3:255-258

Midgeley M (1984) Animals and why they matter. University of Georgia Press, Athens

Morrison A (2001) A scientist's perspective on the ethics of using animals in behavioral research. In: Carroll M, Overmier JB (2001) Animal research and human health. American Psychological Association, Washington D.C.

Morrison A (2002) Developing an ethical view on the use of animals in biomedical research. Physiologist 45:135-144

Orlans FB (2002) Ethical themes of the national regulations governing animal experiments: an international perspective. In: Gluck JP, DiPasquale T, Orlans FB (eds) Applied ethics in animal research: philosophy, regulation, and laboratory applications. Purdue University, West Lafayette

Overall KL (1994) Use of clomipramine to treat ritualistic motor behavior in dogs. J Am Vet Assoc 205:1733-1741

Regan T (1983) The case for animal rights. University of California, Berkeley

Roberts LW, Warner T, Brody J (2000) Perspectives of schizophrenia patients and psychiatrists regarding ethically important aspects of research participation. Am J Psychiatry 157:67-74

Rollin B (1989) The unheeded cry: animal consciousness, animal pain and science. Oxford University, New York

Russell W, Burch R (1959) The principles of humane experimental technique. Methuen, London

Sapontzis S (1987) Morals, reasons and animals. Temple University, Philadelphia

Shenger-Krestovnikova NR (1921) Contributions to the question of differentiation of visual stimuli and the limits of differentiation by the visual analyzer of the dog. Bull Lesgaft Inst Petrograd 3:1-43

Singer P (1975) Animal liberation: a new ethics for the treatment of animals. New York Review, New York

Singer P (1990) Animal liberation: a new ethics for the treatment of animals, 2nd edn. New York Review, New York

Willner P (1995) Animal models of depression: validity and applications. In: Gessa G, Fratta W, Pani L, Serra G (eds) Depression and mania: from neurobiology to treatment. Raven, New York, pp 1941 